\title{
Oxoanion Binding by Flexible Guanidiniocarbonyl Pyrrole-Ammonium Bis-Cations in Water.
}

\author{
Carsten Schmuck* and Volker Bickert
}

Universität Würzburg, Institut für Organische Chemie, Am Hubland, 97074 Würzburg, Germany, Fax: + 49931 8884625, Email: schmuck@chemie.uni-wuerzburg.de

\section{Table of Contents}

General remarks

${ }^{1} \mathrm{H}$ and (400 MHz, DMSO- $d_{6}$ ) and ${ }^{13} \mathrm{C}$ NMR (400 MHz, DMSO- $d_{6}$ ) spectra of the following compounds:

Figure 1: bis-cation 1 with $\mathrm{C}_{2} \mathrm{H}_{4}$-spacer

Figure 2: bis-cation 2 with $\mathrm{C}_{3} \mathrm{H}_{6}$-spacer

Figure 3: bis-cation 3 with $\mathrm{C}_{4} \mathrm{H}_{8}$-spacer

Figure 4: bis-cation 4 with $\mathrm{C}_{5} \mathrm{H}_{10}$-spacer

Figure 5: bis-cation 5 with Lys-spacer

Figure 6: 5-( $t$ Boc-Guanidiniocarbonyl)-1H-pyrrole-2-carboxylic acid benzylester $8 \quad 8$

Figure 7: 5-(tBoc-Guanidiniocarbonyl)- $1 H$-pyrrole-2-carboxylate 9

ITC-spectrum of the titration of $\mathbf{3}$ with phenyl alanine:

Figure 8 
General remarks: Solvents were dried and distilled before use. The starting materials and reagents were used as obtained from the commercial suppliers. All experiments were run in oven-dried glassware. The compounds were dried in high vacuum over phosphorus pentoxide at room temperature overnight unless otherwise stated. The $\mathrm{pH}$ values were measured at $25{ }^{\circ} \mathrm{C} .{ }^{1} \mathrm{H}$ and ${ }^{13} \mathrm{C}$ NMR spectra were recorded on a $400 \mathrm{MHz}$ spectrometer. The chemical shifts are reported relative to the deuterated solvents. All UV spectra were measured in 10 mm rectangular quartz cuvettes. 

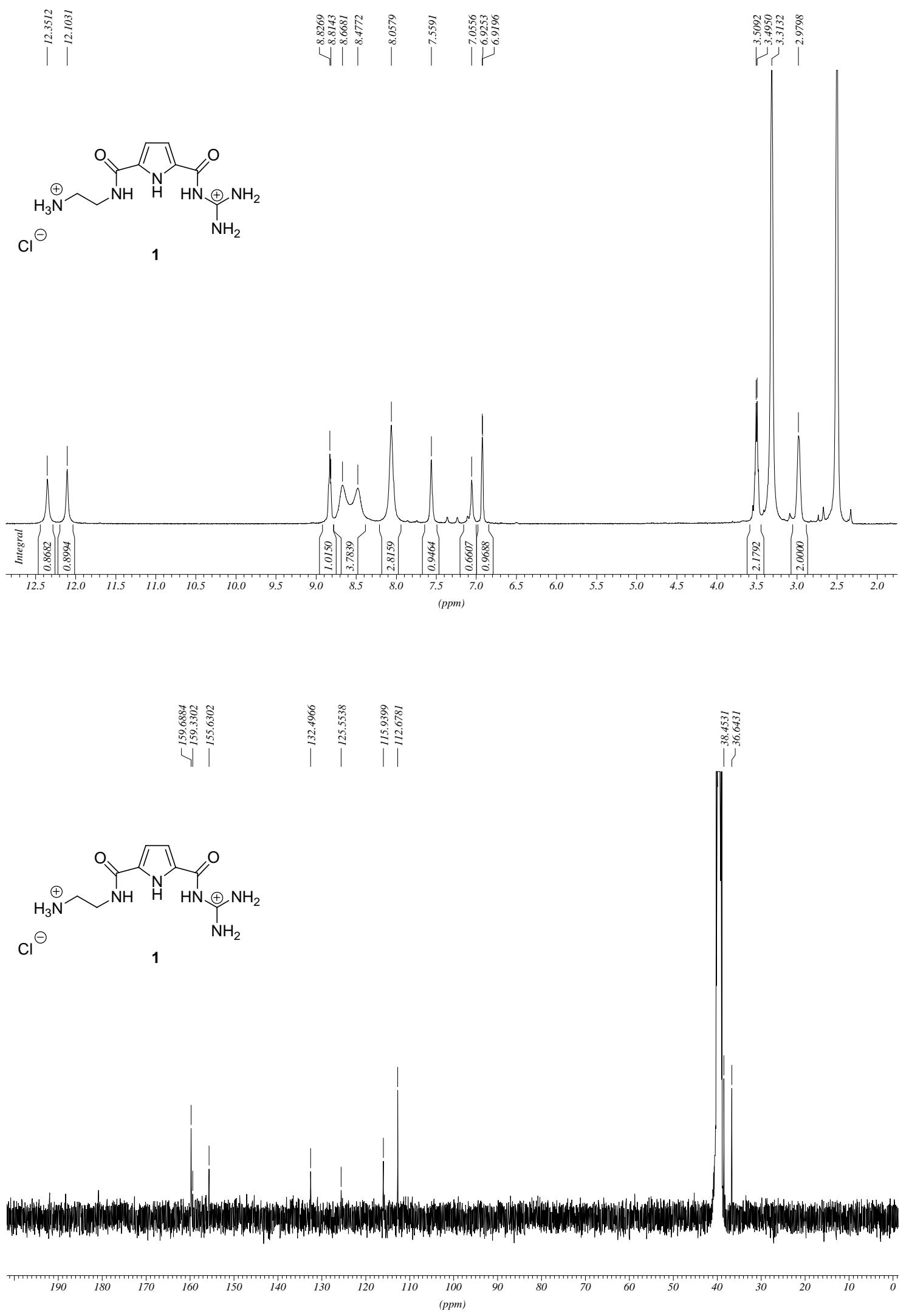

Figure 1: ${ }^{1} \mathrm{H}$ and (400 MHz, DMSO- $d_{6}$ ) and ${ }^{13} \mathrm{C}$ NMR (400 MHz, DMSO- $d_{6}$ ) of bis-cation 1 with $\mathrm{C}_{2} \mathrm{H}_{4}$-spacer. 

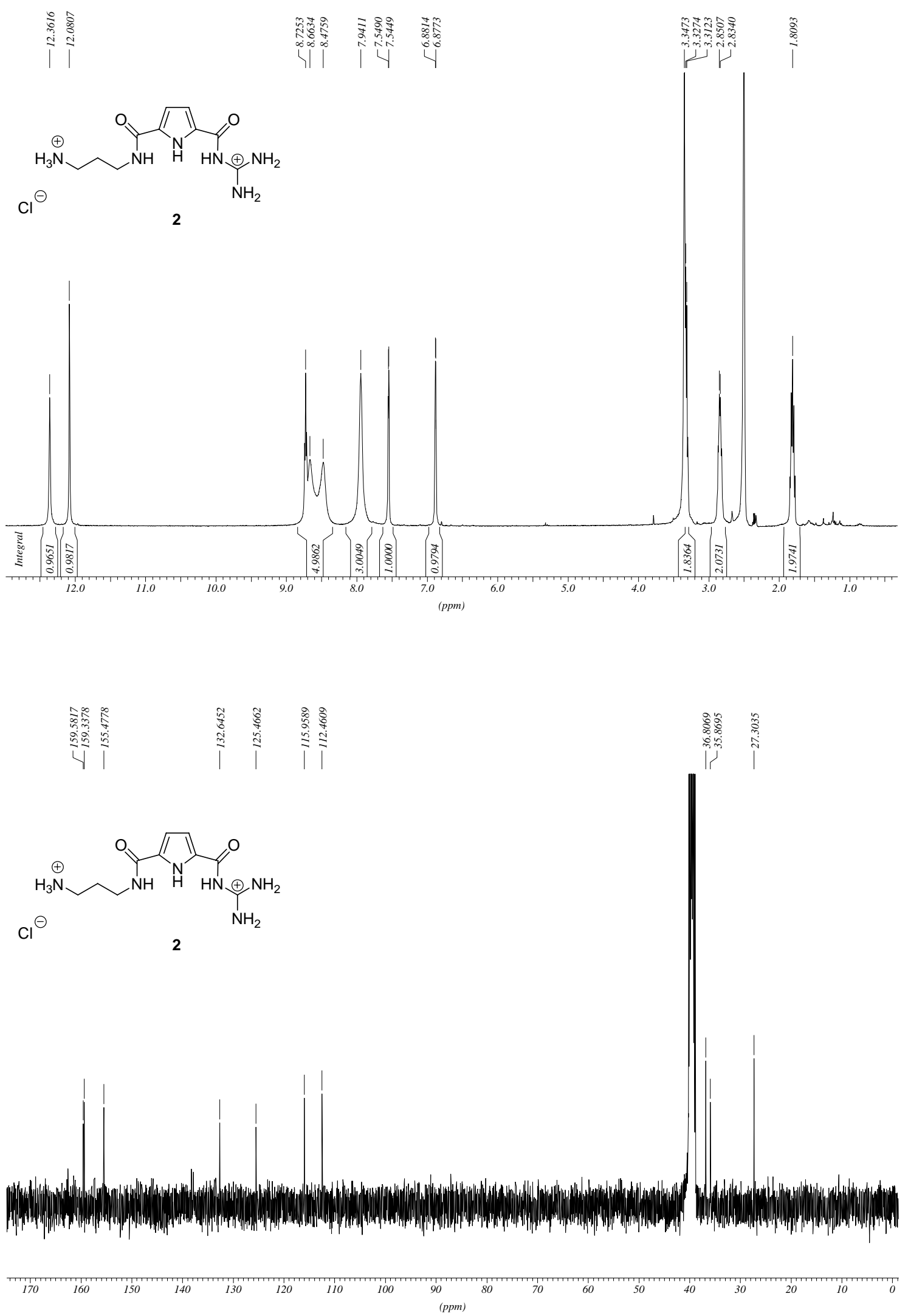

Figure 2: ${ }^{1} \mathrm{H}$ and (400 MHz, DMSO- $d_{6}$ ) and ${ }^{13} \mathrm{C}$ NMR (400 MHz, DMSO- $d_{6}$ ) of bis-cation 2 with $\mathrm{C}_{3} \mathrm{H}_{6}$-spacer. 

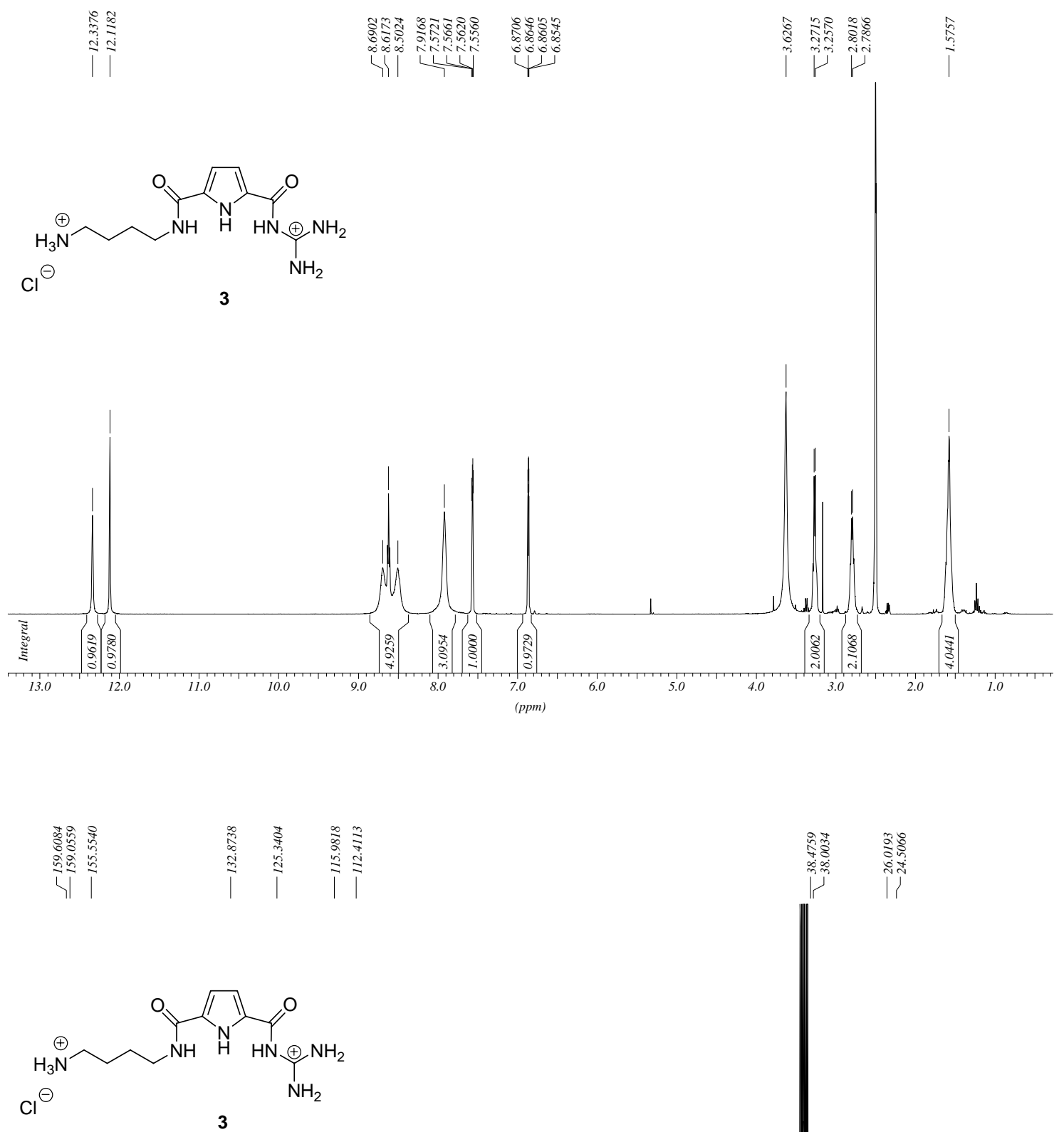

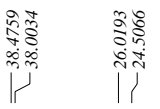

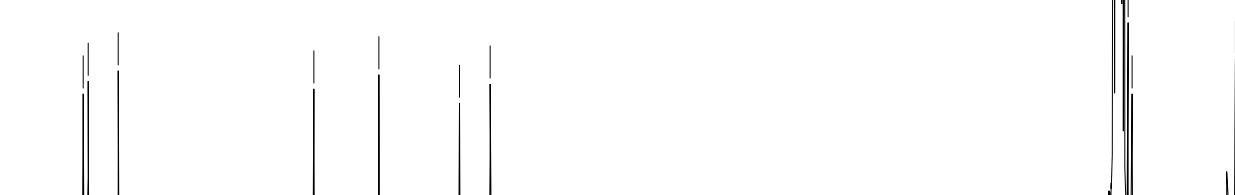

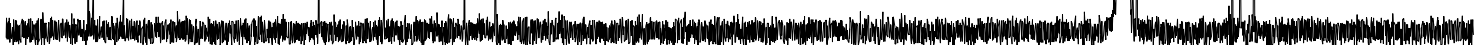

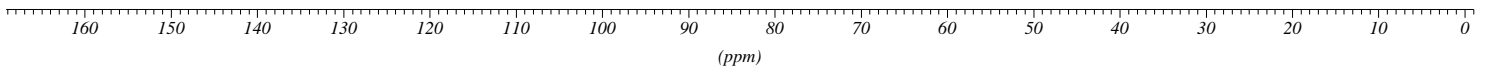

Figure 3: ${ }^{1} \mathrm{H}$ and $\left(400 \mathrm{MHz}\right.$, DMSO- $d_{6}$ ) and ${ }^{13} \mathrm{C}$ NMR (400 MHz, DMSO- $d_{6}$ ) of bis-cation 3 with $\mathrm{C}_{4} \mathrm{H}_{8}$-spacer. 

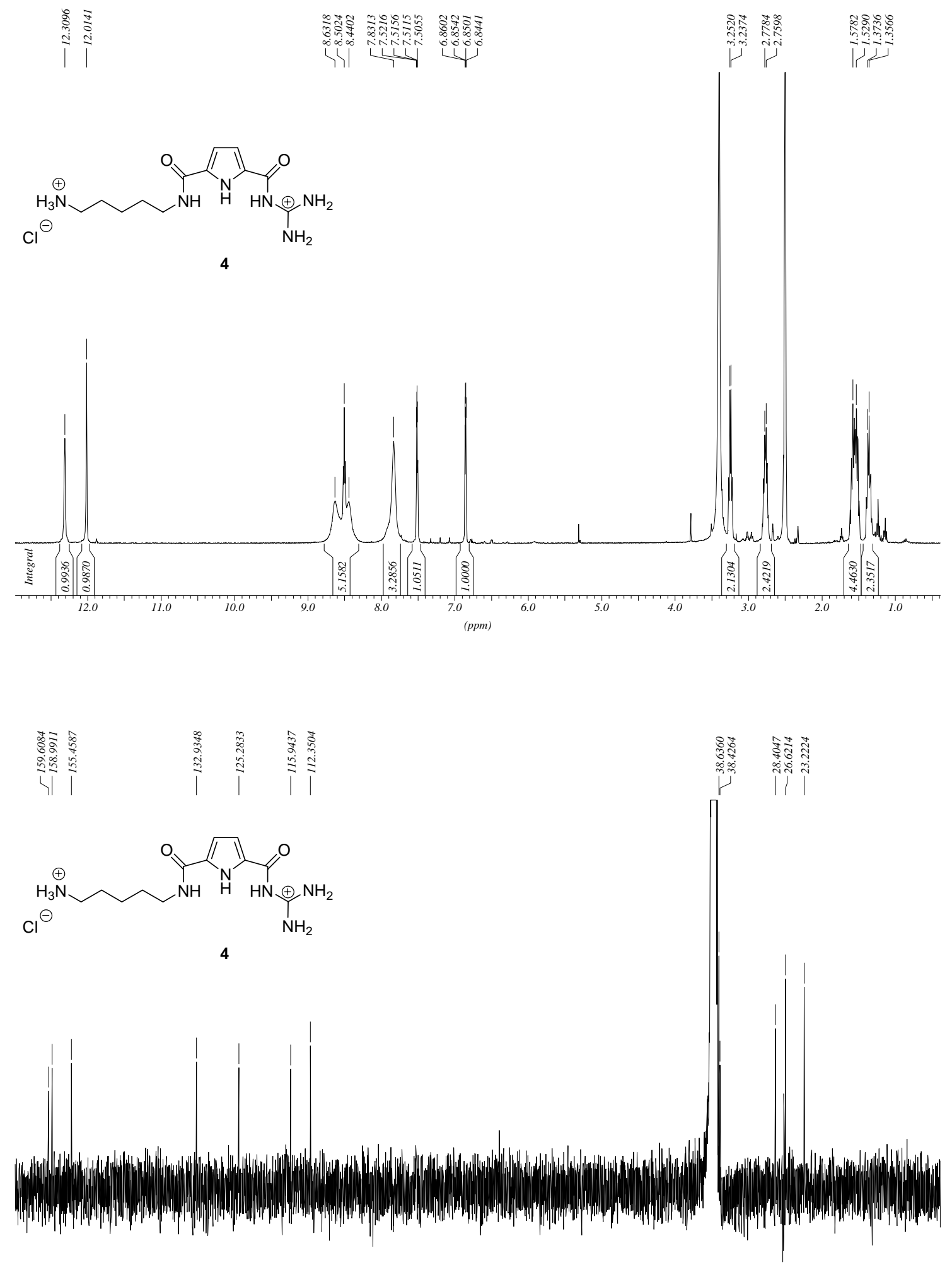

\begin{tabular}{|c|}
\hline 100 \\
\hline
\end{tabular}

Figure 4: ${ }^{1} \mathrm{H}$ and (400 MHz, DMSO- $d_{6}$ ) and ${ }^{13} \mathrm{C}$ NMR (400 MHz, DMSO- $d_{6}$ ) of bis-cation 4 with $\mathrm{C}_{5} \mathrm{H}_{10}$-spacer. 

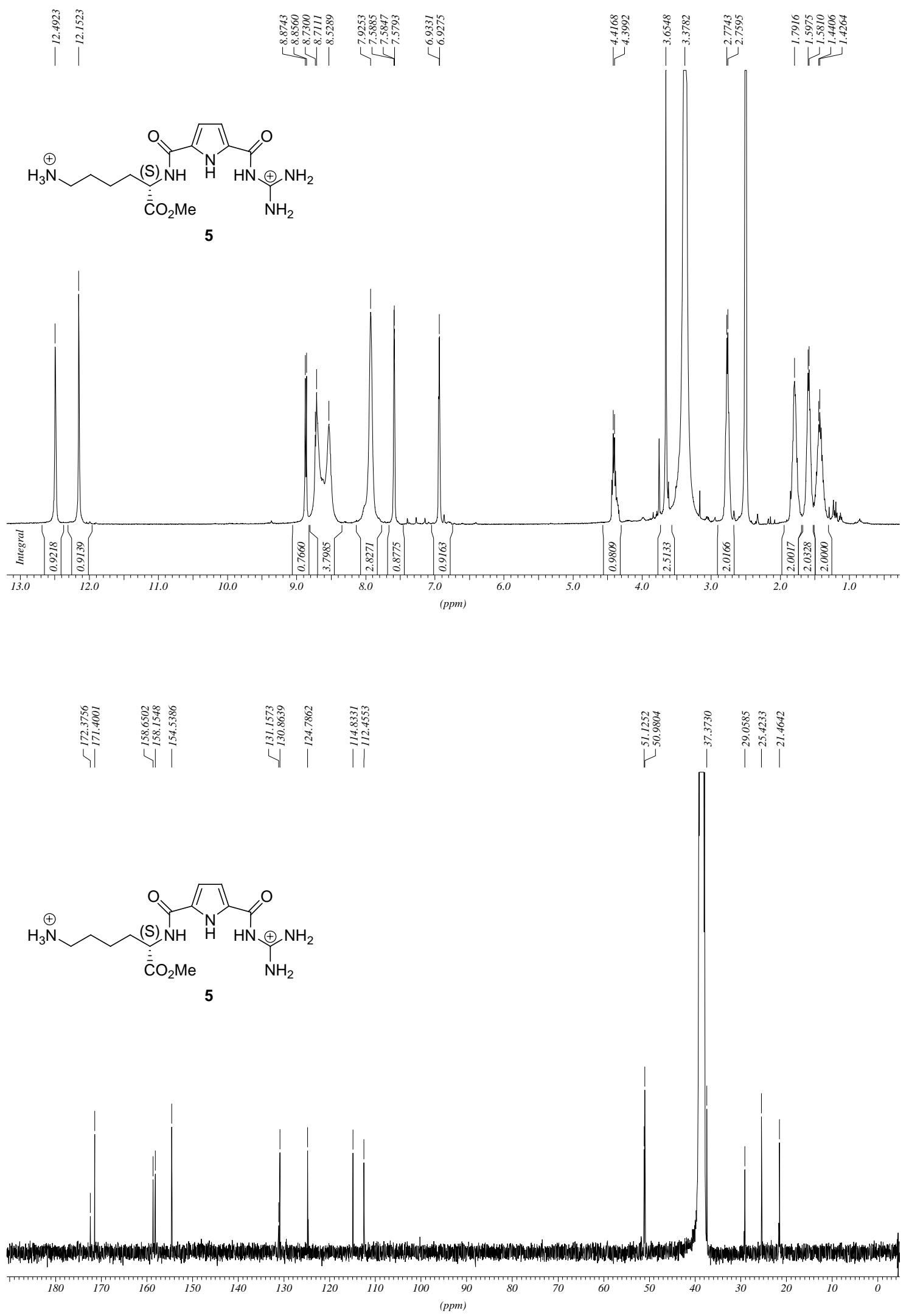

Figure 5: ${ }^{1} \mathrm{H}$ and (400 MHz, DMSO- $\left.d_{6}\right)$ and ${ }^{13} \mathrm{C}$ NMR (400 MHz, DMSO- $d_{6}$ ) of bis-cation 5 with Lys-spacer. 

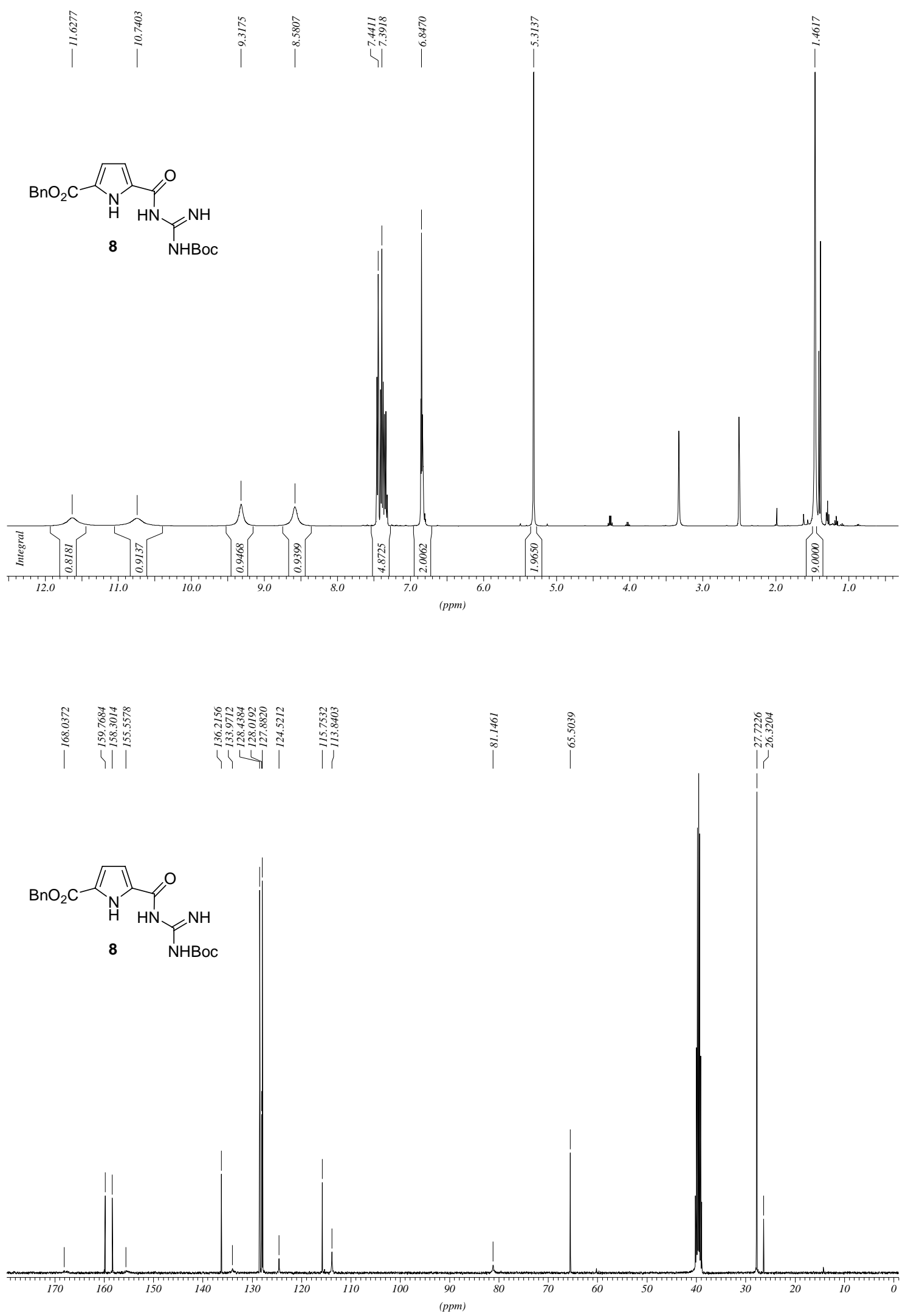

Figure 6: ${ }^{1} \mathrm{H}$ and (400 MHz, DMSO- $\left.d_{6}\right)$ and ${ }^{13} \mathrm{C}$ NMR (400 MHz, DMSO- $\left.d_{6}\right)$ of 5-((tertbutyloxycarbonyl)-Guanidiniocarbonyl)-1H-pyrrole-2-carboxylic acid benzylester $\mathbf{8}$. 

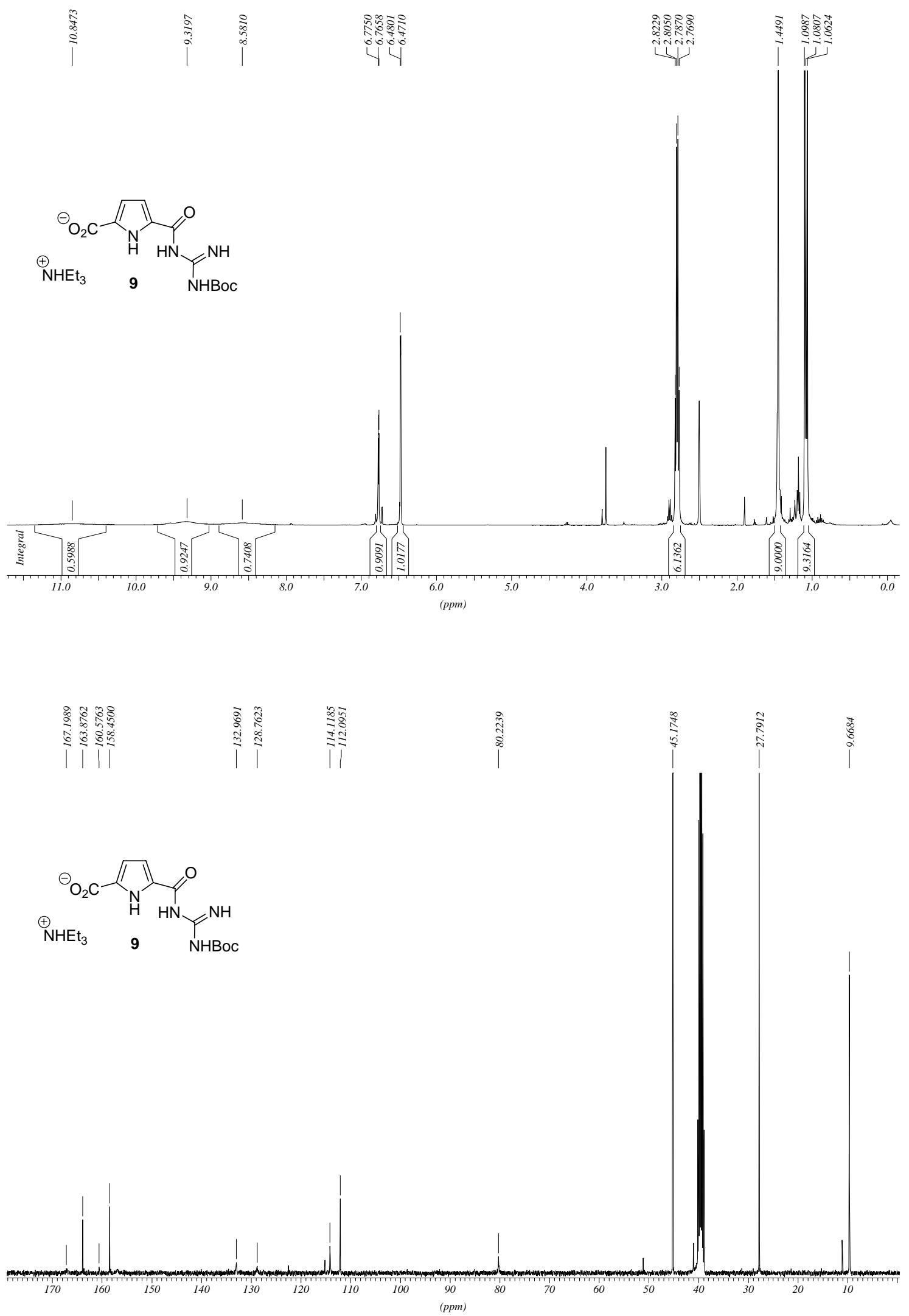

Figure 7: ${ }^{1} \mathrm{H}$ and (400 MHz, DMSO- $\left.d_{6}\right)$ and ${ }^{13} \mathrm{C}$ NMR (400 MHz, DMSO- $\left.d_{6}\right)$ of 5-((tertbutyloxycarbonyl)-Guanidiniocarbonyl)-1H-pyrrole-2-carboxylate 9 


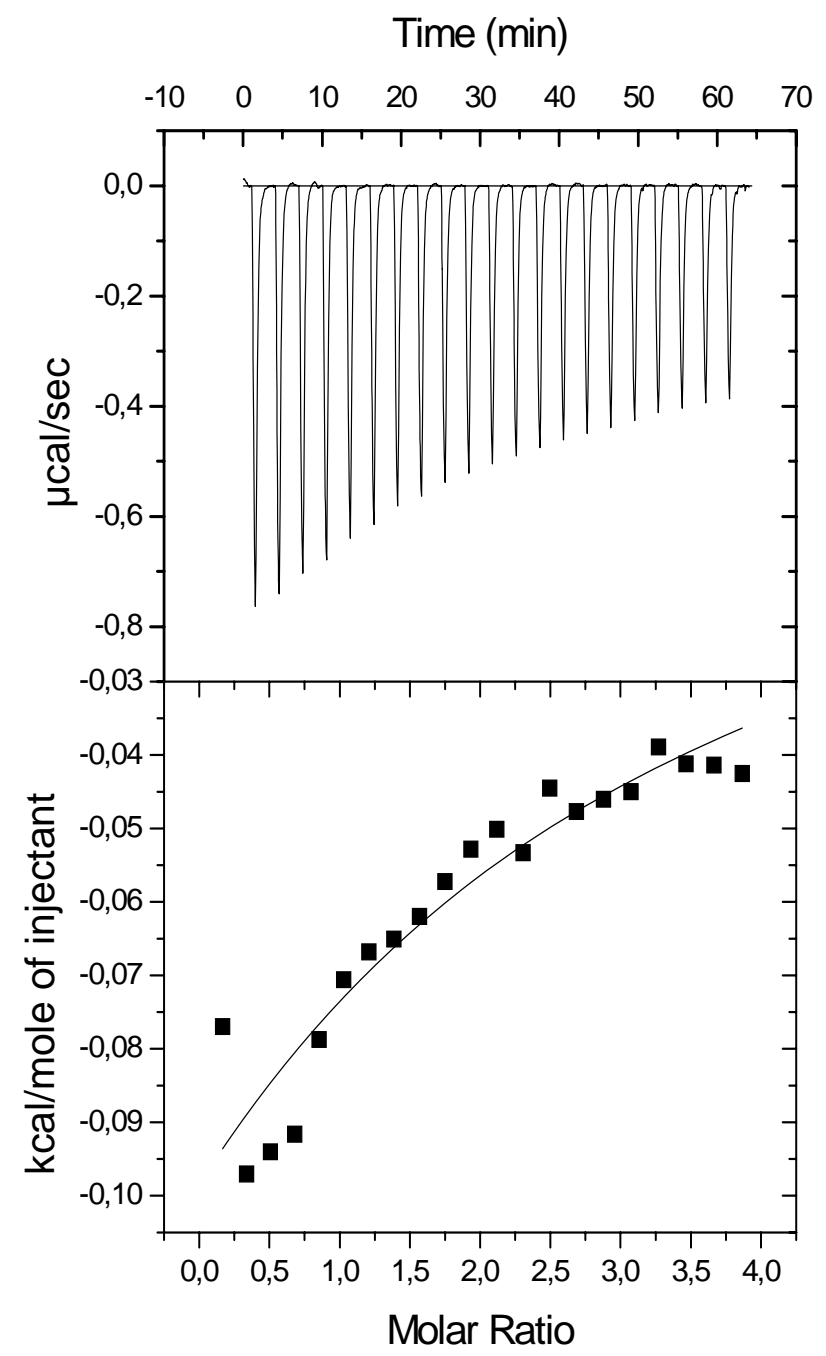

Figure 8: Top: ITC-spectrum of the titration of receptor 3 with $\mathrm{N}$-acetyl phenyl alanine carboxylate. The released heat of the reaction is plotted against the molar ratio at $25^{\circ} \mathrm{C}$. As solvent a one to one mixture of methanol and water with a $20 \mathrm{mM}$ bis-tris buffer at $\mathrm{pH} 6.00$ was used. The concentration of 3 was $0.6 \mathrm{mM}$ whereas phenyl alanine had a concentration of $10 \mathrm{mM}$. Bottom: Resulting binding isotherm after subtracting the dilution-energies of the receptor 3 and phenyl alanine. 